\title{
Glucose deprivation, oxidative stress and peroxisome proliferator-activated receptor- $\alpha$ (PPARA) cause peroxisome proliferation in preimplantation mouse embryos
}

\author{
Sarah Jansen, Kara Cashman ${ }^{1}$, Jeremy G Thompson ${ }^{1}$, Marie Pantaleon and Peter L Kaye \\ School of Biomedical Sciences, The University of Queensland, Brisbane, Queensland 4072, Australia and ${ }^{1}$ School of \\ Paediatrics and Reproductive Health, Discipline of Obstetrics and Gynaecology, Medical School, Research Centre for \\ Reproductive Health, University of Adelaide, Adelaide, South Australia 5005, Australia
}

Correspondence should be addressed to P L Kaye; Email: p.kaye@uq.edu.au

S Jansen is now at Education Program in Reproduction and Development, Monash Institute of Medical Research, 27-31 Wright Street, Clayton, Victoria 3168, Australia

\begin{abstract}
Ex vivo two-cell mouse embryos deprived of glucose in vitro can develop to blastocysts by increasing their pyruvate consumption; however, zygotes when glucose-deprived cannot adapt this metabolic profile and degenerate as morulae. Prior to their death, these glucose-deprived morulae exhibit upregulation of the $\mathrm{H}^{+}$-monocarboxylate co-transporter SLC16A7 and catalase, which partly co-localize in peroxisomes. SLC16A7 has been linked to redox shuttling for peroxisomal $\beta$-oxidation. Peroxisomal function is unclear during preimplantation development, but as a peroxisomal transporter in embryos, SLC16A7 may be involved and influenced by peroxisome proliferators such as peroxisome proliferator-activated receptor- $\alpha$ (PPARA). PCR confirmed Ppara mRNA expression in mouse embryos. Zygotes were cultured with or without glucose and with the PPARA-selective agonist WY14643 and the developing embryos assessed for expression of PPARA and phospho-PPARA in relation to the upregulation of SLC16A7 and catalase driven by glucose deprivation, indicative of peroxisomal proliferation. Reactive oxygen species (ROS) production and relationship to PPARA expression were also analysed. In glucose-deprived zygotes, ROS was elevated within $\mathbf{2}$ h, as were PPARA expression within $8 \mathrm{~h}$ and catalase and SLC16A7 after 12-24 h compared with glucose-supplied embryos. Inhibition of ROS production prevented this induction of PPARA and SLC16A7. Selective PPARA agonism with WY14643 also induced SLC16A7 and catalase expression in the presence of glucose. These data suggest that glucose-deprived cleavage stage embryos, although supplied with sufficient monocarboxylate-derived energy, undergo oxidative stress and exhibit elevated ROS, which in turn upregulates PPARA, catalase and SLC16A7 in a classical peroxisomal proliferation response.

Reproduction (2009) 138 493-505
\end{abstract}

\section{Introduction}

Glucose deprivation is a potent cell stressor leading to the activation of cell death pathways. The totipotent cells of cleavage stage preimplantation embryos rely on monocarboxylates, pyruvate and lactate for energy during the first few divisions after fertilization (Brinster 1965, Wilding et al. 2002). Indeed, $5.6 \mathrm{mM}$ glucose can be toxic at this time, and thus media used to culture human embryos in assisted reproductive procedures contain only very low glucose concentrations (for reviews see Biggers 1998, Lane \& Gardner 2007). Gradually, co-incident with the initiation of the first differentiation into epithelial trophectoderm, glucose becomes a major ATP source. For preimplantation embryos in vivo, the conversion from monocarboxylate-based to glucose-based generation of ATP is induced by prior exposure to glucose, which is provided in the oviductal milieu (Gardner et al. 1996, Harris et al. 2005), but this supply can be manipulated in vitro. This unusual metabolic profile presents a model for the investigation of cellular stress response induced by glucose deprivation. Subtle changes in embryo culture conditions can increase cell death and may be associated with increased reactive oxygen species (ROS) activity.

Although not used for fuel, glucose is catabolized by early cleavage stage embryos through the hexosamine biosynthetic pathway (Pantaleon et al. 2008) and the pentose phosphate pathway, producing amino sugar nucleotides and nucleic acid precursors that may be required for cell proliferation and NADPH generation. $\mathrm{NADPH}$ is predominantly used in triacylglycerol synthesis, of which there is little supporting evidence in these embryos, and in reduction of oxidized 
glutathione to support glutathione peroxidase management of hydrogen peroxide $\left(\mathrm{H}_{2} \mathrm{O}_{2}\right)$. So we reasoned that if stress was applied by glucose deprivation, pentose phosphate pathway flux would cease and the cells' ability to generate NADPH so as to reduce ROS would be compromised, thus potentiating further increases in cellular ROS and activation of peroxisome proliferation in order to respond.

Peroxisomes, first noted in rat oocytes in situ (Figueroa et al. 2000) and subsequently in mouse preimplantation embryos (Jansen et al. 2008), both produce and scavenge ROS and house enzymes for fatty acid $\beta$-oxidation (Piot et al. 1998) of which there is some evidence in embryos (Kane 1979, Hillman \& Flynn 1980, Quinn \& Whittingham 1982, Haggarty et al. 2006). Interestingly, SLC16A7 and catalase co-localize to embryonic peroxisomes and are upregulated in embryos deprived of glucose, which later degenerate before blastulation (Jansen et al. 2008). Much of this increased SLC16A7 was found in peroxisomes rather the plasma membrane, suggesting a role in ROS metabolism. This increased peroxisomal activity suggests that glucose deprivation may result in oxidative stress activating peroxisome proliferation.

Oxidative stress arises from an elevation in ROS including superoxide anions $\left(\mathrm{O}_{2}^{-}\right)$or $\mathrm{H}_{2} \mathrm{O}_{2}$ from various sources. Brief exposure of embryos to $\mathrm{H}_{2} \mathrm{O}_{2}$ inhibits cell proliferation and causes arrest before blastulation (Cebral et al. 2007). Similar consequences follow from early periods of glucose deprivation in vitro (Sakkas et al. 1989, Brown \& Whittingham 1991, Chatot et al. 1994, Martin \& Leese 1995). At the heart of peroxisomal proliferation is the activity of the peroxisome proliferator-activated receptors (PPAR). These ligand-activated nuclear receptors or transcription factors affect transcription of a range of peroxisome-related genes. Not surprisingly, PPARs are responsible for regulating catabolism of fats and glucose homeostasis (Lemberger et al. 1996b). There are three subtypes: PPARA, abundant in liver and kidney; PPARG mostly in adipose and intestinal tissue and both are activated by second messengers from the arachidonic cascade pathways. PPARB/D is constitutive to all tissues and by contrast activated preferentially by unsaturated fatty acids (Braissant et al. 1996, Lemberger et al. 1996a, Krey et al. 1997).

This study investigated PPARA in the metabolic stress response of early embryos because of its previously established role in fatty acid oxidation, its upregulation in response to oxidative stress (Schrader \& Fahimi 2006) and after fasting (Gremlich et al. 2005) and in later stage ovine embryos after maternal nutrient restriction (Bispham et al. 2005, Budge et al. 2005). The fibrate WY14643, a PPARA agonist that causes peroxisomal proliferation in rodents via activation of PPARA (Nemali et al. 1989, Shearer \& Hoekstra 2003), was used to test our hypothesis that complete glucose deprivation induced oxidative stress in the embryo with resultant induction of PPARA, SLC16A7 and catalase.

\section{Results}

\section{Induction and phosphorylation of PPARA}

Ovulated oocytes and zygotes collected at $18 \mathrm{~h}$ posthuman chorionic gonadotrophin (hCG) express Ppara mRNA, which persists during culture until the two-cell stage, but could not be detected in ex vivo morulae $(72 \mathrm{~h}$ post-hCG) or blastocysts (96 $\mathrm{h}$ post-hCG) that would develop from these zygotes (Fig. 1A). When embryos were collected and cultured, those supplied with glucose reflected this in vivo pattern of repression in morulae, but a weak signal persisted in glucose-deprived morulae. Studies to locate the protein were more informative. In zygotes, PPARA staining was predominantly distributed diffusely through the cytoplasm and this pattern persisted through development (Fig. 1B-I). Quantitative image analysis showed little change in PPARA over $4 \mathrm{~h}$ of culture, but by $8 \mathrm{~h}$ there was increased PPARA protein in glucose-deprived embryos, while glucose-supplied embryos showed a slight decrease in PPARA staining that persisted until $54 \mathrm{~h}$ post culture to the morula stage (Fig. 1G-J). Also after $8 \mathrm{~h}$ of glucose deprivation (Fig. 1G), staining became more granular and this more granular pattern persisted over the next $46 \mathrm{~h}$ (Fig. 1G-I).

Phosphorylation of PPARA was monitored with an antiserum against PPARA-phospho-Ser12 (Fig. 1K). Over the $4-24 \mathrm{~h}$ period, the most dramatic change was a decrease $(48 \%, P<0.01)$ in cellular PPARAphospho-Ser12 staining in embryos supplied with glucose, while there was no significant change in glucose-deprived embryos. Indeed, as total PPARA levels in glucose-supplied embryos remained fairly constant through this period (Fig. 1J), the decrease in PPARA-phospho-Ser12 suggests dephosphorylation of PPARA in embryos growing under these normal conditions. In contrast, in glucose-deprived embryos, total PPARA increased 24\% (Fig. 1J), while the level of PPARA-phospho-Ser12 was constant suggesting that in these embryos, although overall PPARA was induced, a smaller proportion was phosphorylated. However, the site of PPARA activity is in the nucleus, so nuclear levels of PPARA-phospho-Ser21 were examined against PPARA at $24 \mathrm{~h}$ with dual staining and quantitation (Fig. 1L-N). It was clear that PPARA-phospho-Ser21 concentrated about twofold in the nuclei of glucosedeprived embryos. So assuming both PPARA-phosphoSer12 and PPARA-phospho-Ser21 behave similarly, this suggests that glucose deprivation produces cell stress leading to increased PPARA expression and greatly increased recruitment of the activated PPARA into the chromatin, possibly with contingent peroxisome proliferation. Meanwhile, embryos developing with glucose showed reduced phospho-PPARA and reduced PPARA, suggesting a quiescent metabolism (Fig. 1J and K). 
A
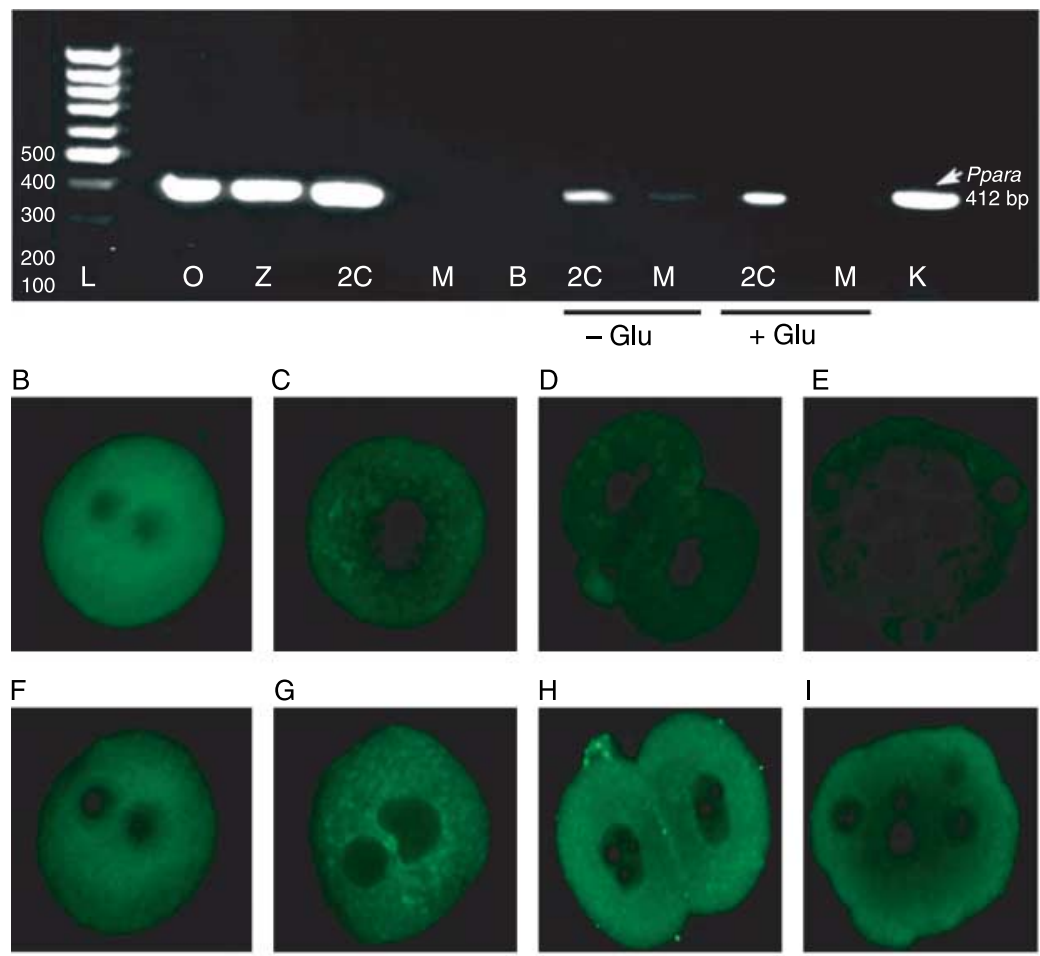

G
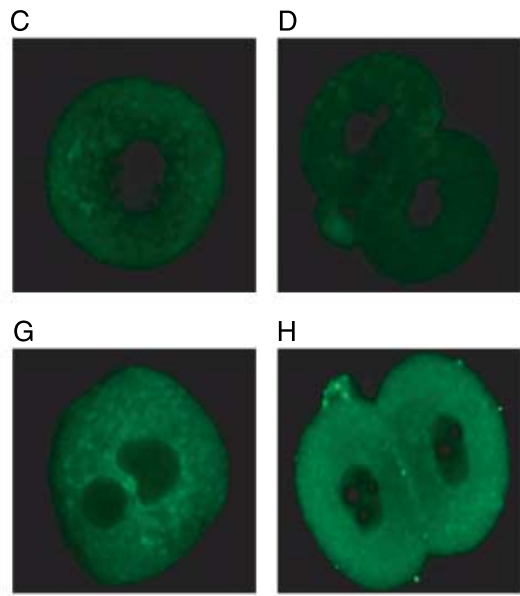

E

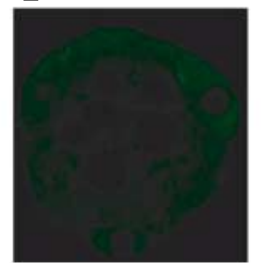

$\mathrm{H}$
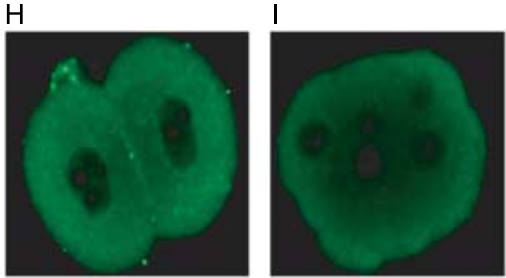

$J$

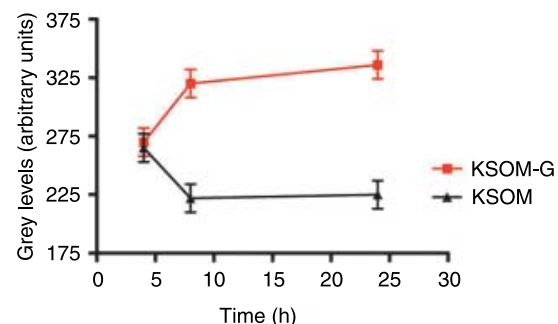

L

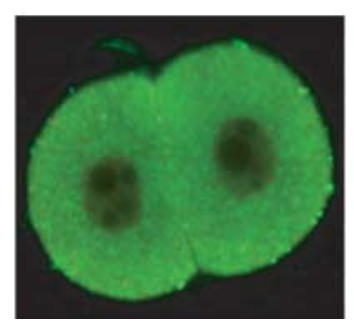

Ksom
K

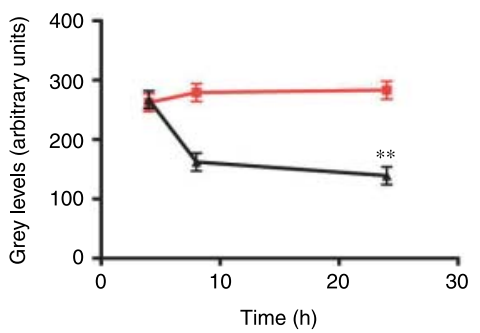

N

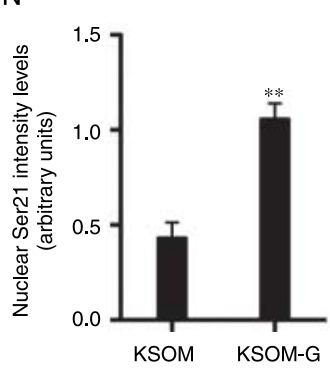

Figure 1 PPARA mRNA and immunoreactivity in Quackenbush mouse embryos. (A) PCR for Ppara in CDNA from pools of 100 embryos per lane demonstrated an expected 412-bp band in freshly isolated oocytes and two-cell embryos as well as in two-cell embryos following in vitro culture for $24 \mathrm{~h}$ in KSOM with or without glucose (L, 1 kb ladder; $\mathrm{O}$, unfertilized oocytes; $\mathrm{Z}$, zygotes; $2 \mathrm{C}$, two-cell embryos; $\mathrm{M}$, morulae; $\mathrm{B}$, blastocysts; $\mathrm{K}$, mouse kidney homogenate). In embryos collected at $18 \mathrm{~h}$ post-hCG and cultured for $60 \mathrm{~h}$, Ppara mRNA was detected in glucose-deprived morulae (-Glu), but not in glucose-supplied morulae (+Glu). Embryos collected at $18 \mathrm{~h}$ post-hCG and cultured in KSOM were also assessed by immunofluorescence using polyclonal rabbit anti-mouse antibodies, pan-PPARA or PPARA-phosphoSer12. Immunoreactivity for pan-PPARA is diffusely cytoplasmic at all embryo stages (B-E: 4, 8, 24 and $54 \mathrm{~h}$ post-culture respectively), but its intensity is reduced to absent in morulae (E) and blastocysts (not shown).

Glucose-deprived embryos exhibit similar diffuse cytoplasmic staining for pan-PPARA (F-I: 4, 8,24 and $54 \mathrm{~h}$ post-culture), but the intensity was increased from $8-54 \mathrm{~h}$ post-culture $(\mathrm{G}-\mathrm{l})$ compared with glucose-supplied embryos (C-E). Levels of PPARA were quantified and averaged to yield one value per embryo. A minimum of three embryos per treatment in each of three experiments was assayed in this way, and data were also presented for both pan-PPARA $(\mathrm{J})$ and PPARA-phopho-Ser12 immunoreactivity (K). Interestingly, while total levels of PPARAphospho-Ser12 appear to be stable in glucosedeprived embryos and decline in those cultured with glucose (K), using an antiserum against PPARA-phospho-Ser21 (red) and dual immunolabelling with pan-PPARA (green) demonstrate that nuclear PPARA-phospho-Ser21 is elevated in the glucose-deprived two-cell embryos ( $L$ and $M$ ) within $24 \mathrm{~h}$ of culture. ${ }^{* *} P<0.01$, Quantified and presented as mean nuclear phospho-PPAR immunoreactivity from each of two nuclei in minimum of five embryos per treatment in each of three experiments.

\section{Catalase}

To investigate this possibility, the effects of the peroxisome proliferator WY14643 on transcription and translation of a classic peroxisomal marker, catalase, were examined (Fig. 2). In all embryos, cytoplasmic staining was diffuse and granular with these vesicles distributed in the cortical cytoplasm. Catalase immunoreactivity was more intense and granules were more pronounced and numerous in glucose-deprived embryos and embryos treated with the PPAR activator WY14643 in the presence of glucose. Catalase expression was acutely sensitive to glucose deprivation or PPARA activation; as by $4 \mathrm{~h}$ of treatment, catalase protein was already elevated by about 20\% (Fig. $2 \mathrm{~A}, P<0.01$ ). Degradation of about $10 \%$ of the protein over $12 \mathrm{~h}$ was revealed by inhibition of translation with 
A

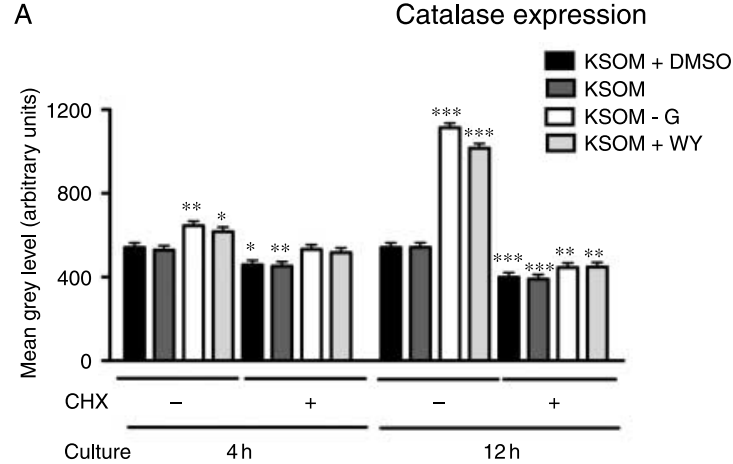

C

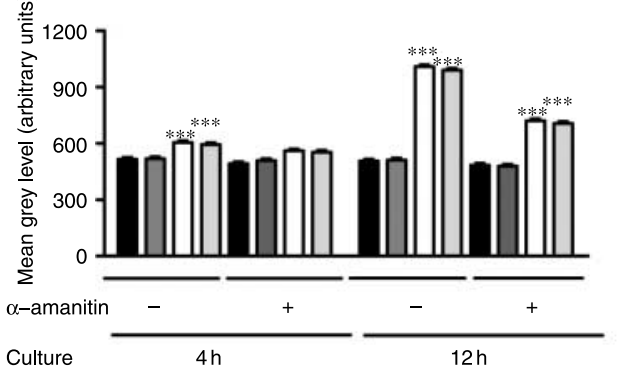

B

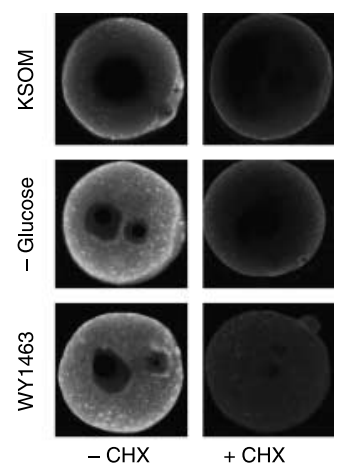

D

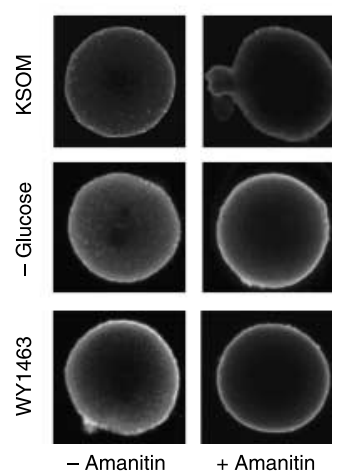

Figure 2 Effect of cycloheximide (CHX) (A) and $\alpha$-amanitin $(\mathrm{C})$ on catalase expression in response to the presence or absence of glucose. Embryos were cultured from $18 \mathrm{~h}$ post-hCG, and catalase immunoreactivity was assessed and quantified in response to treatment as described using immunofluorescence. Results represent the mean \pm S.E.M. grey scale intensity per embryo from a minimum of three embryos per treatment, in each of three experiments (A and C). ${ }^{*} P<0.05$; ${ }^{* *} P<0.01$; ${ }^{* * *} P<0.001$ by ANOVA and Bonferroni post-test relative to control treatments (KSOM+DMSO) in each time point. Representative images of catalase immunoreactivity following $12 \mathrm{~h}$ culture in response to indicated treatments are also shown. When glucose was supplied (KSOM), catalase immunoreactivity appears localized to cytoplasmic granules and submembranous regions and is increased in response to glucose deprivation or treatment with $10 \mu \mathrm{M}$ WY14643. While $2 \mu \mathrm{g} / \mathrm{ml}$ cycloheximide abolished this increase (A and $B)$, inclusion of $1 \mu \mathrm{g} / \mathrm{ml} \boldsymbol{\alpha}$-amanitin in the medium in parallel culture experiments demonstrates only partial inhibition of this stimulated increase (C and D). cycloheximide $(\mathrm{CHX} ; P<0.001)$. Both glucose deprivation and PPARA activation increased the total pool of catalase, by increased transcription and translation $(P<0.01$, Fig. $2 \mathrm{~A}-\mathrm{D})$, but there was evidence of an inhibition of catalase turnover as even in the presence of $\alpha$-amanitin, expression was increased by $50 \%$ after $12 \mathrm{~h}$ $(P<0.001)$.

\section{SLC16A7}

As we had already observed that SLC16A7 was located in embryonic peroxisomes, it was similarly examined to determine whether it was under PPAR regulation (Fig. 3). Both plasma membrane and granular cytoplasmic staining were $30 \%$ more intense in glucosedeprived embryos $(P<0.001)$, but SLC16A7 was not as acutely responsive as catalase (Figs 2 and 3). Studies with the protein synthesis inhibitor $\mathrm{CHX}$ revealed no loss of SLC16A7 over $12 \mathrm{~h}$ in glucose-supplied embryos (Fig. $3 \mathrm{~A}$ and $\mathrm{B}, P>0.05)$, but the $57 \%(P<0.001)$ increase in expression induced by $12 \mathrm{~h}$ of glucose deprivation required both transcription and translation, suggesting transcription was activated by the glucose deprivation. The PPAR activator WY14643 produced similar increases in SLC16A7 transcription and translation to glucose deprivation, indicating that both glucose deprivation and PPARA activation induce SLC16A7 expression via transcription as well as translation.

\section{Reactive oxygen species}

The peroxisomal proliferation indicated by increased catalase and induction of PPARA induced by glucose deprivation suggested that this nutrient manipulation is a stressor, and it was hypothesized that this might be reflected in increased intracellular ROS. When these were assessed after only $2 \mathrm{~h}$, ROS levels had risen by about $20 \%(P<0.05)$ in glucose-deprived embryos or embryos stimulated with peroxisome proliferator (Fig. 4). Two hours later, while the ROS peak in the glucosedeprived embryos had abated, it persisted in the peroxisome proliferator-treated embryos, indicating a more persistent induction. To confirm a role for peroxide production in this ROS peak, the experiment was repeated using diphenyleneiodonium (DPI) to inhibit flavoenzymes, particularly NADPH oxidase, and so decelerate the ROS synthesis resulting from glucose deprivation. Again, in the glucose-deprived and PPARA agonist-treated zygotes, ROS levels were about 20\% greater than for zygotes developing with glucose (KSOM), but inhibition of flavoenzymes with DPI prevented or reduced this elevated ROS arising from glucose deprivation or PPARA agonism (Fig. 5).

\section{Effect of DPI on PPARA and SLC16A7 expression}

This suggested that the induction of PPARA might be downstream from the increased ROS. So some embryos from each group were left in culture for 8 or 24 h, before 
A
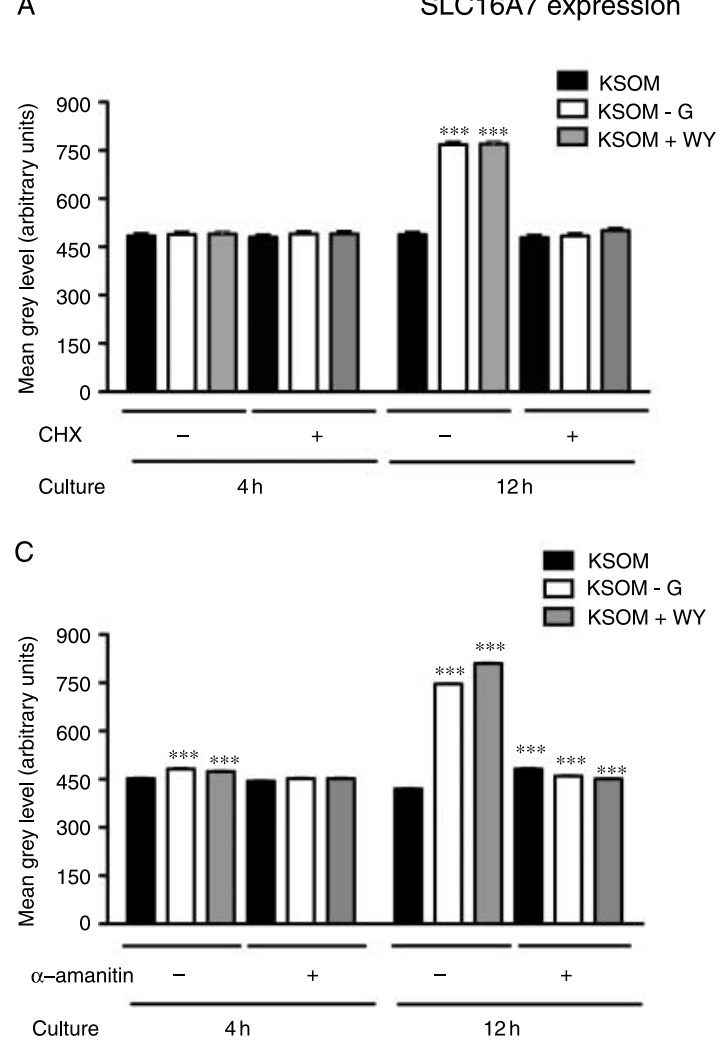

B

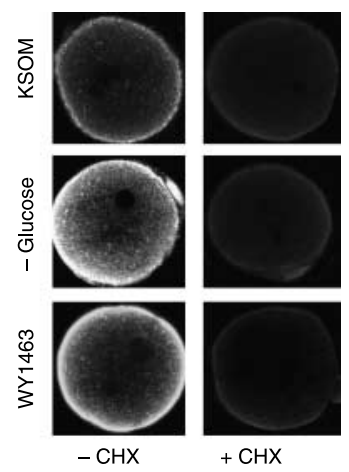

D

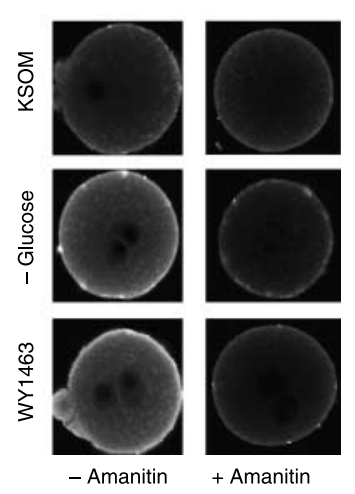

Figure 3 Effect of cycloheximide (A) and $\alpha$-amanitin (C) on SLC16A7 expression in response to the presence or absence of glucose. Embryos were cultured from $18 \mathrm{~h}$ posthCG and SLC16A7 immunoreactive expression was assessed and quantified as described. Results represent the mean \pm S.E.M. grey scale intensity per embryo from a minimum of three embryos per treatment, in each of three experiments (A and $\mathrm{C}$ ); ${ }^{* * *} P<0.001$ by ANOVA and Bonferroni post-test relative to control treatment within each time point. Representative images of SLC16A7 immunoreactivity following $12 \mathrm{~h}$ of culture in response to indicated treatments are also shown. When glucose was supplied (KSOM), SLC16A7 immunoreactivity, which appears localized to cytoplasmic granules as well as on the plasma membrane, is elevated both in response to glucose deprivation and treatment with $10 \mu \mathrm{M}$ PPARA agonist WY14643. While treatment of embryos with both $2 \mathrm{mg} / \mathrm{ml}$ cycloheximide and $1 \mu \mathrm{g} / \mathrm{ml} \alpha$-amanitin had no apparent effect at $4 \mathrm{~h}$ of culture, both treatments completely inhibit this stimulated increase in SLC16A7 expression following $12 \mathrm{~h}$ of culture (C and D). they were fixed and subsequently assessed by immunofluorescence for either PPARA (at 8 h, Fig. 6) or SLC16A7 (24 h, Fig. 7). Mean grey levels in zygotes cultured in KSOM (Figs 6A and 7A and white bars in corresponding graphs) were accepted as control levels, and all other mean grey levels were compared with controls. In glucose-deprived zygotes (Fig. 6B and graph), PPARA immunoreactivity was about $15 \%$ more intense $(P<0.05)$, DPI completely blocked this increase (Fig. 6C), but was ineffective on the quantitatively similar WY14643 induction of PPARA (Fig. 6D and $E$ and graph). This pattern was replicated by SLC16A7, except that the glucose deprivation (Fig. $7 \mathrm{~B}$ and graph) or WY14643 induction (Fig. 7D and graph) was almost $150 \%$ in both cases, possibly reflecting the different times of observation, $8 \mathrm{~h}$ for PPARA and $24 \mathrm{~h}$ for SLC16A7.

\section{Discussion}

Although reliant upon monocarboxylates rather than glucose for ATP production, cleavage stage mammalian embryos are exquisitely tuned to glucose supply. Given that glucose deprivation is a potent cell stressor, that glucose can act as a signalling molecule to permit metabolic differentiation (Pantaleon et al. 2008) and that glucose deprivation increases partly peroxisomal
SLC16A7 expression (Jansen et al. 2008), we set out to examine the impact of glucose deprivation on early embryonic oxidative stress.

\section{PPARA, SLC16A7 and catalase}

PPARA is a nuclear receptor from the steroid receptor superfamily (Issemann \& Green 1990) activated by concurrent dimerization with RXR, phosphorylation of specific sites (including Ser12 and Ser21) and the attachment of activating ligands, including unsaturated fatty acids and derivatives of the lipooxygenase route of the arachidonic acid cascade (Diradourian et al. 2005). Activation of PPARA tends to induce further expression of PPARA (Sharifpanah et al. 2008) and subsequent peroxisome proliferation, including the transcription of peroxisomal $\beta$-oxidation-encoding genes such as acylCoA oxidase, multifunctional protein and thiolase (Bardot et al. 1995).

Never examined in preimplantation embryos, PPARA has been detected in mouse embryonic stem (ES) cells (Sharifpanah et al. 2008) that originate as pluripotent cells of the inner cell mass (ICM) of the day 4 embryo or blastocyst where they are completely isolated from the external/maternal milieu by the epithelial trophectoderm. ICM cells convert all glucose supplied via the trophectoderm to lactate (Hewitson \& Leese 1993). 


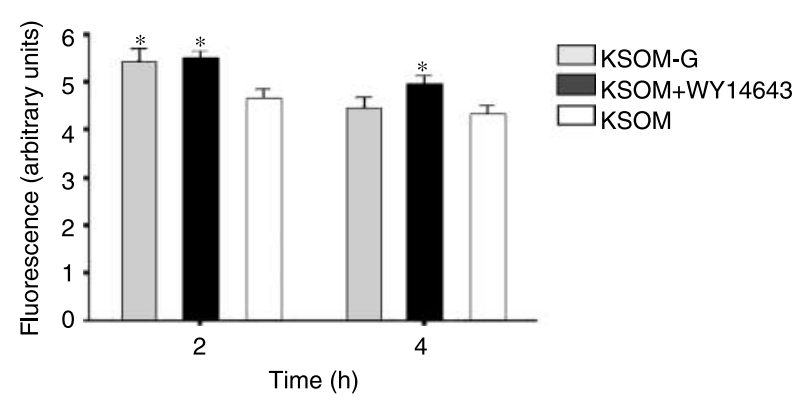

Figure 4 ROS production in mouse embryos deprived of glucose. Mouse embryos (CBA/F1) were collected at $18 \mathrm{~h}$ post-hCG, cultured for 2 or $4 \mathrm{~h}$ in standard KSOM, KSOM-lacking glucose (KSOM-G) or KSOM with $10 \mu \mathrm{M}$ WY14643 and ROS assayed as described in Materials and Methods. Data represent mean fluorescence of culture groups divided by mean fluorescence of average esterase activity from randomly sampled embryos. Within $2 \mathrm{~h}$ of culture, ROS levels in glucosedeprived embryos or WY14643-treated embryos are higher than those in embryos cultured in standard $\operatorname{KSOM}\left({ }^{*} P<0.05\right)$. While the ROS levels remain high in the presence of $W Y 14643$ at $4 \mathrm{~h}$ post-culture $\left({ }^{*} P<0.05\right)$, in glucose-deprived embryos they decline to reach levels not significantly different from glucose-supplied embryos $(P>0.05)$.

Ppara mRNA is expressed in the zygote and two-cell mouse embryo, but cannot be detected in pooled cDNA from the equivalent of four morulae cultured with glucose. Similarly, the protein disappears from glucose-supplied embryos as they develop through the cleavage stages in vitro. But if embryos are glucose deprived, the mRNA persists in morulae and the protein is upregulated after $8 \mathrm{~h}$ deprivation. Moreover, glucose deprivation prevented the dephosphorylation of PPARAphospho-Ser12 that occurs when glucose is supplied. More importantly, it doubled the concentration of nuclear phospho-PPARA at $24 \mathrm{~h}$, consistent with increased transcriptional activity associated with, among other things, peroxisome proliferation. This pattern was replicated when glucose-supplied embryos were treated with the PPARA agonist WY14643. So one mechanism triggered by glucose deprivation involves nuclear recruitment of phospho-PPARA with consequent peroxisomal proliferation and likely metabolic re-orientation. In different cells and with different stimuli, phosphorylation can activate or deactivate PPARA (Gelman et al. 2005). Supporting these results, there is evidence that glucose deprivation stabilizes PPARA mRNA, reducing its degradation, and increases mRNA levels for PPARGC1A, a major co-activator of PPARA (Bogdanova et al. 2007). Several groups have reported upregulation of PPARA activity in response to fasting (Sterchele et al. 1996, Hashimoto et al. 2000, Escher et al. 2001, Sugden et al. 2001) and in sheep, maternal nutrient restriction between 28 and 80 days gestation induced PPARA expression in offspring (Bispham et al. 2005, Budge et al. 2005). In addition to this induction and activation by glucose deprivation, PPARA activation rapidly increased PPARA levels by parallel selfinduction of transcription and also through inhibited polyubiquitination and proteasomal degradation (Hirotani et al. 2001).

Results herein demonstrate that PPARA activation induced SLC16A7 expression even when glucose was supplied, because transcriptional and translational inhibitors had the same degree of inhibition of induction. This suggests that activated PPARA, possibly phospoPPARA, acts to promote SLC16A7 expression. SLC16A7 has not been identified as a target protein for peroxisome proliferation, but PPARs affect target genes by binding to a specific DR1 motif in a peroxisome proliferatorresponse element (PPRE) located upstream in the promoter region (Latruffe et al. 2000). A brief assessment of the Slc16A7 gene identified such a DR1 sequence as well as sites for many stress-associated transcription factors such as: GATA; CREB; FKHD; HIF; and NFKB (Table 1), providing further support for the conclusion that the PPARA activation is upstream of SLC16A7 induction. Because of the association of MCT with peroxisomes and peroxisomal metabolism, it is likely that SLC16A7 is induced along with other key peroxisomal proteins during peroxisomal proliferation.

Catalase, on the other hand, appeared to have different regulatory modes from SLC16A7. Both glucose deprivation and PPARA agonism (WY14643) increased catalase expression even after $4 \mathrm{~h}$ of culture. These results are supported by evidence of PPARA induction upregulating catalase (Nemali et al. 1989) and the existence of a functional PPRE in the catalase promoter (Girnun et al. 2002). As in mouse zygotes, in both these studies, $\alpha$-amanitin treatment only marginally reduced the increase in catalase immunoreactivity, suggesting

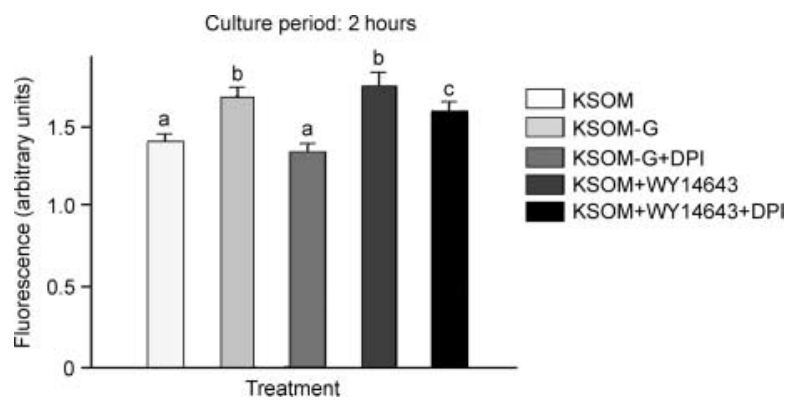

Figure 5 Effect of DPI on embryonic ROS production. CBA/F1 mouse zygotes were collected at $18 \mathrm{~h}$ post-hCG, cultured for $2 \mathrm{~h}$ in standard KSOM, KSOM-lacking glucose, KSOM-lacking glucose with $0.1 \mu \mathrm{M}$ DPI, KSOM with $10 \mu \mathrm{M}$ WY14643 in DMSO, KSOM with $10 \mu \mathrm{M}$ WY14643 in DMSO and 0.1 $\mu \mathrm{M}$ DPI, KSOM with DMSO 1:10 000. They were then assayed for ROS as described in Materials and Methods. Data represent mean fluorescence of culture groups divided by mean fluorescence of average esterase activity from randomly sampled embryos. The addition of DPI into the media of glucosedeprived embryos reduced ROS levels in these embryos to a level that not statistically different from that in glucose-supplied embryos. In embryos cultured with WY14643, DPI reduced ROS levels, but they remained significantly higher than those in glucose-supplied embryos. Means with different superscripts are significantly different $(P<0.05)$. Results from embryos cultured in KSOM+DMSO 1:10 000 were not statistically different from KSOM alone (not shown). 

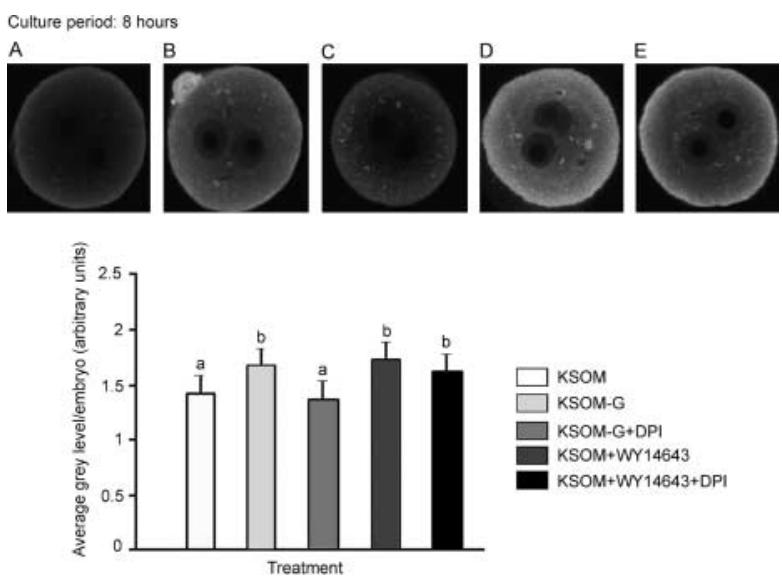

Figure 6 Effect of DPI on embryonic PPARA. Three experimental sets of CBA/F1 mouse embryos cultured for $8 \mathrm{~h}$ under varied conditions were fixed and underwent simultaneous immunocytochemistry for PPARA. Immunoreactivity for PPARA in all embryos was diffused throughout the cytoplasm and stained weakly in nuclei, but was noticeably absent from nucleoli. Representative embryos from groups cultured in: KSOM (A, glucose supplied), KSOM-lacking glucose (B, glucose deprived), KSOM-lacking glucose with $0.1 \mu \mathrm{M}$ DPI (C), KSOM with $10 \mu \mathrm{M}$ WY14643 in DMSO (D), KSOM with $10 \mu \mathrm{M}$ WY14643 in DMSO and $0.1 \mu \mathrm{M} \mathrm{DPI}(\mathrm{E})$ are shown. The average grey levels for glucose-deprived embryos or treated with WY14643 were higher than for glucosesupplied embryos. When DPI was added to glucose-deprived embryos, the pan-PPARA staining was reduced to levels not statistically different from that of glucose-supplied embryos. This was not the case for embryos cultured with WY14643 and DPI, where pan-PPARA staining remained elevated. Means with different superscripts are significantly different $(P<0.05)$.

a more complex regulation of catalase involving transcriptional and post-transcriptional levels. This evidence has been confirmed in many investigations that have identified post-transcriptional controls for catalase activity (Yano et al. 1998, 2004, Yano \& Yano 2002, Cao et al. 2003, Vivancos et al. 2004). There is evidence that proteasomal degradation of catalase in response to stress is increased in a biphasic pattern via a pathway involving activation of the ABL1 non-receptor tyrosine kinase and the product of the $A B L 1$-related gene (Arg). It may be that the level of $\mathrm{H}_{2} \mathrm{O}_{2}$ generated in the glucose-deprived embryos was insufficient to promote binding of ABL1 and Arg to catalase thus increasing stability (Cao et al. 2003). Additionally, because embryonic genome activation does not occur until the mid-late two-cell stage, it is possible that a greater part of catalase induction relies on pre-formed maternal mRNA delivered in the oocyte and not yet degraded.

Glucose deprivation by preventing pentose phosphate pathway flux and NADPH production induces ROS leading to PPARA induction and peroxisome proliferation. However, PPARA activation similarly leads to ROS and peroxisome proliferation. Investigation herein of the source of ROS in embryos using the NADPH oxidase inhibitor, DPI, revealed attenuation of the ROS peak generated by PPARA agonists, but not completely. In contrast, in mouse ES cells, WY14643-induced activation of PPARA caused ROS elevation that was attenuated with DPI, but not the mitochondrial electron transport inhibitor rotenone (Sharifpanah et al. 2008). However, it is possible that the extended ROS peak produced by the PPARA agonist might arise from the contribution of ROS arising from sources other than those involved in glucose deprivation-induced ROS. It has been demonstrated that hepatocytes in NADPH oxidase-deficient ( $p 47^{p h o x}$-null) mice treated with WY14643 still exhibit acute increased ROS with a rapid increase in oxidative DNA damage and increased cell proliferation, a response that is potentially mediated through nuclear factor kappa B (Woods et al. 2007). These observations may explain why the DPI protocol was ineffective in reducing ROS levels in agonist-treated embryos to the same extent as those deprived of glucose. Alternatively, the extended ROS peak may arise from $\beta$-oxidation of lipids (Piot et al. 1998, Teissier et al. 2004, Poirier et al. 2006). The $10 \mu \mathrm{M}$ WY14643 used in these experiments is likely to be far in excess of the concentration of activated PPARA induced by glucose deprivation, and it is not unreasonable to assume that exaggerated oxidative stress is occurring in this situation. Studies in rat liver have shown that PPARA induction by

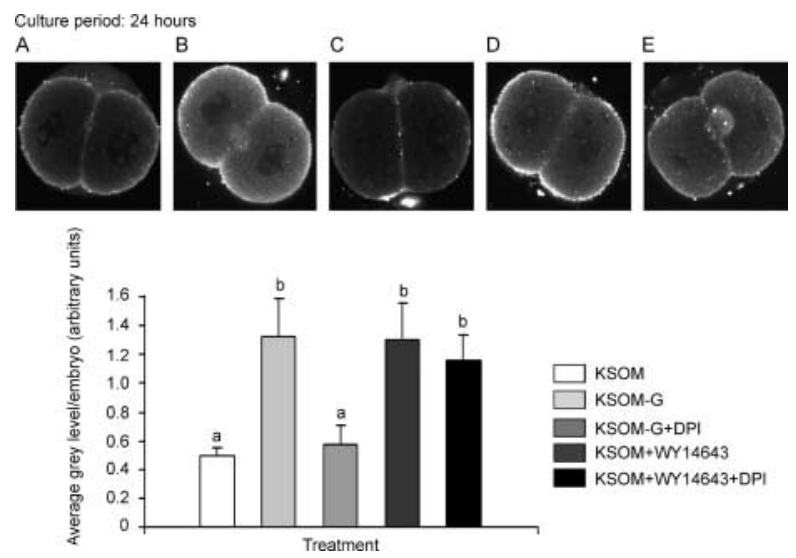

Figure 7 Effect of DPI on embryonic SLC16A7. Three experimental sets of CBA/F1 mouse embryos cultured for $24 \mathrm{~h}$ under varied conditions were fixed and underwent simultaneous immunocytochemistry for SLC16A7. In all embryos, SLC16A7 staining was located on the plasma membrane and in the cytoplasm as stippling or tiny granules.

Representative embryos from groups cultured in: KSOM (A, glucose supplied), KSOM-lacking glucose (B, glucose deprived), KSOM-lacking glucose with $0.1 \mu \mathrm{M} \mathrm{DPI}(\mathrm{C}), \mathrm{KSOM}$ with $10 \mu \mathrm{M}$ WY14643 in DMSO (D), KSOM with $10 \mu \mathrm{M}$ WY14643 in DMSO and $0.1 \mu \mathrm{M}$ DPI (E) are shown. When quantified, SLC16A7 staining in glucose-deprived embryos or in glucose-supplied embryos treated with WY14643 was higher than for embryos cultured in KSOM alone. When DPI was added to glucose-deprived embryos, SLC16A7 staining was reduced to levels not statistically different from those of glucose-supplied embryos. This was not the case for embryos treated with WY14643 and DPI whose SLC16A7 staining remained significantly elevated. Means with different superscripts are significantly different $(P<0.05)$. 
Table 1 Putative transcription regulatory sequences in the $2.4 \mathrm{~kb}$ region upstream of the mouse S/c16a7 gene.

\begin{tabular}{|c|c|c|c|c|c|}
\hline Matrix name & Position $^{a}$ & Strand $( \pm)^{b}$ & Core similarity & Matrix similarity & $\begin{array}{l}\text { Sequence (capitals: core } \\
\text { sequence) }\end{array}$ \\
\hline PPAR/RXR DR1 site & $31-53$ & $(-)$ & 1.000 & 0.950 & gttcttcaGGAAgagagagca \\
\hline \multirow[t]{6}{*}{ GATA } & 197-209 & $(+)$ & 1.000 & 0.968 & tccaGATAatctg \\
\hline & $516-528$ & $(-)$ & 1.000 & 0.963 & tggaGATAaagga \\
\hline & $1181-1193$ & $(-)$ & 1.000 & 0.970 & tccaGATAggtag \\
\hline & $1806-1818$ & $(+)$ & 1.000 & 0.976 & aacAGATctaaac \\
\hline & $2158-2170$ & $(-)$ & 1.000 & 0.916 & ggaAGATttaaaa \\
\hline & $2382-2394$ & $(+)$ & 1.000 & 0.934 & gggAGATcataaa \\
\hline \multirow[t]{4}{*}{ CREB } & $247-267$ & $(-)$ & 1.000 & 0.990 & ttgtgttGACGtgcaatattc \\
\hline & 379-399 & $(-)$ & 1.000 & 0.900 & cacagcTGATgtagatgagct \\
\hline & $1186-1206$ & $(-)$ & 1.000 & 0.941 & acaataTGACgtttccagata \\
\hline & $2287-2307$ & $(-)$ & 1.000 & 0.905 & acttcaTGACttaatatcaaa \\
\hline \multirow[t]{3}{*}{ FKHD } & $250-266$ & $(+)$ & 1.000 & 0.834 & tgcacgtcAACAcaaag \\
\hline & 1808-1824 & $(+)$ & 1.000 & 0.904 & cagatcTAAAcaggacg \\
\hline & $2361-2377$ & $(+)$ & 1.000 & 0.787 & tctacgaaAACActgag \\
\hline \multirow[t]{2}{*}{ HIF } & $247-263$ & $(-)$ & 1.000 & 0.942 & tgtgttgaCGTGcaata \\
\hline & $2091-2107$ & $(-)$ & 1.000 & 0.923 & gttttctaCGTGcacca \\
\hline \multirow[t]{3}{*}{ NFKB } & $360-372$ & $(-)$ & 1.000 & 0.996 & ttgggggtTTCCt \\
\hline & $651-663$ & $(+)$ & 1.000 & 0.937 & gcGGGAggtccca \\
\hline & $652-664$ & $(-)$ & 1.000 & 0.938 & atGGGAcctcccg \\
\hline
\end{tabular}

The $2.4 \mathrm{~kb}$ sequence upstream of the Slc16a7 ATG of the mouse sequence (GenBank: NM_011391) was analysed by Matlnspector, a transcription factor database.

${ }^{a}$ The positions of the putative binding sites are shown as the distance $(\mathrm{bp})$ from the first nucleotide of the mouse S/c16a7 promoter region (GenBank: NM_011391). ${ }^{\text {b The }}(+)$ and $(-)$ indicate that the putative motifs are located on the plus or minus strands of this upstream $2.4 \mathrm{~kb}$ sequences.

peroxisome proliferators produces differential regulation of peroxisomal enzymes (Nemali et al. 1989, Yeldandi et al. 2000). WY14643, in particular, induced a 20-fold increase in the genes encoding peroxide-generating enzymes like fatty acyl-CoA oxidase and cytochrome P450 (CYP) 4A isoforms for peroxisomal $\beta$-oxidation within $30 \mathrm{~min}$ to $1 \mathrm{~h}$, while catalase displayed only a 2 -fold increase. This results in overwhelming generation of $\mathrm{H}_{2} \mathrm{O}_{2}$ within peroxisomes, with possible overflow into the cytoplasm.

While there is very little information on peroxisomal activity in embryos, it is pertinent to note that a knockout model for the mitochondrial fatty acid oxidation enzyme long-chain acyl-CoA dehydrogenase (LCAD) appears to block mouse embryo development at the morula stage (Berger \& Wood 2004). This group demonstrated that $\mathrm{LCad}^{-/-}$embryos cannot complete the development of a blastocoele and formation of a blastocyst, and subsequently degenerate at the morula stage, similarly to embryos deprived of glucose. Supplementation with shorter chain fatty acids that could be readily oxidized did not rescue development, suggesting that longer chain fatty acid oxidation does occur and plays a vital role in mouse development. LCAD and many other mitochondrial $\beta$-oxidation enzymes (L-type carnitine palmitoyltransferase I and medium-chain acyl-CoA dehydrogenase) are regulated by PPARA (Ringseis et al. 2007). This brings an interesting insight into our experiments. It seems that while PPARA appears to be activated in the presence of glucose, this in itself is not enough to overcome the block to development. Perhaps this is because mouse embryos at this early stage do not have enough fatty acid stores to derive enough energy via $\beta$-oxidation. The addition of exogenous medium and long-chain fatty acid substrates in the absence of glucose may have allowed these embryos to progress. This question needs further study.

The importance of fatty acid oxidation to early development is further illustrated by the benefits to blastulation of supplementation with long-chain fatty acids in rabbit (Kane 1979) and mouse (Quinn \& Whittingham 1982); while in mice, palmitic acid oxidation, constant until the eight-cell stage, accelerates as blastulation progresses (Hillman \& Flynn 1980), providing a metabolic explanation for this benefit. In humans, palmitic acid uptake increases to the morula stage before declining co-incidentally with increased linoleic acid uptake and blastulation (Haggarty et al. 2006). Supporting evidence for preimplantation peroxisomal function now exists in the present association of SLC16A7 with oxidative stress induced by glucose deprivation or PPARA activation. SLC16A7 might exist in the peroxisomal membrane to facilitate pyruvate import for conversion to lactate via peroxisomal $\mathrm{LDH}$. As hypothesized by McClelland et al. (2003) in relation to rat liver peroxisomes, this would enable recycling of $\mathrm{NAD}^{+}$for continued peroxisomal $\beta$-oxidation of longchain fatty acids and lactate export to the cytoplasm could be facilitated by SLC16A7, either for subsequent mitochondrial metabolism or facilitated excretion to the oviduct. Adding further support to this argument, providing high lactate concentrations in the incubation medium reduced not only pyruvate utilization, but also the $\mathrm{NAD}^{+} / \mathrm{NADH}$ ratio (Lane \& Gardner 2000). So it is possible that preimplantation embryos do utilize their peroxisomes for lipid oxidation and that peroxisomal 
proliferation leads to increased ROS production from this source.

The association of PPARA activation and cardiomyogenic inducing transcription factors (Sharifpanah et al. 2008) perhaps reflects metabolic differentiation to lipid oxidation dependent rather than glycolytic, metabolic profile. This is not too different from the requirements of the glucose-deprived cleavage stage embryo that must rely on accelerated uptake of monocarboxylates or perhaps exogenous oocyte-derived lipid. There is evidence in species where oocytes are more lipid loaded than mice, of lipid metabolism being related to developmental potential (Zeron et al. 2001, Boni et al. 2002, Nagano et al. 2006). The analogy between the embryo and ES cells is reinforced by the observation that PPARA activation leads to increased intracellular ROS. In both cases, NADPH oxidase inhibited by DPI contributes to this ROS, but while this is the only ROS source induced in ES cells in embryos, because DPI did not limit ROS concentrations to unstimulated levels, it is likely that other sources also contribute, such as lipid oxidation or mitochondrial respiratory chain. There is a parallelism in the metabolic fate directed by PPARA activation in ES cells and early embryos. ES cells are derived from ICM cells that are known to rely on oxidation of glucose to lactate for energy (Lonergan et al. 2007). The early embryonic cells generate their ATP from of monocarboxylate oxidation. Adult cardiomyocytes oxidize long-chain fatty acids; fetal heart prefers glucose/ lactate (van der Vusse et al. 1992). Metabolic differentiation from the progenitor cells thus must produce increased peroxisomal and associated MCT activity. As this study demonstrates, this is exactly the outcome of fibrate activation of PPARA in totipotent embryonic cells.

The unusual metabolic profile of the early embryo, relying on mitochondrial ATP generation from the monocarboxylic acids such as pyruvate and lactate, has proved a useful model. The small amounts of glucose normally taken up are thought to be metabolized by the pentose phosphate pathway for the maintenance of reducing power in the cell and in nucleic acid and lipid biosynthesis. In this study, glucose deprivation ablates pentose phosphate pathway activity, of itself limiting NADPH production, but also prevents the dynamic rerouting of metabolic flux to the pentose phosphate pathway, which has been proposed as a conserved posttranslational response to oxidative stress (Ralser et al. 2007). This suggests that the use of glucose-deficient media in modern-assisted reproductive technologies might require some experimental re-examination.

We have demonstrated that very early embryonic cells experience glucose deprivation as an acute stressor, despite their novel metabolic reliance on monocarboxylates. Within only $2 \mathrm{~h}$ of glucose deprivation, ROS was elevated, increasing PPARA levels that preceded peroxisomal proliferation. PPARA activation also leads to peroxisomal proliferation and increased ROS.
Interestingly, although not required for energy metabolism, provision of glucose as would be normal in situ does not support induced ROS or peroxisome proliferation, suggesting an important stress monitor role for glucose.

\section{Materials and Methods \\ Ethics}

The Animal Ethics and Experimentation Committees of the University of Queensland and the University of Adelaide approved all experiments on mice. These committees are approved by the National Health and Medical Research Council of Australia.

\section{Media, chemicals and buffers}

\section{Handling media}

M2 medium (Fulton \& Whittingham 1978) modified to contain $0.33 \mathrm{mM}$ sodium pyruvate and $4 \mathrm{~g} / \mathrm{l}$ of BSA (Sigma-Aldrich, fraction V, A-9647) and lacking glucose.

\section{Culture media}

KSOM containing $0.2 \mathrm{mM}$ glucose but no amino acids (Erbach et al. 1994). WY14643 (Sigma-Aldrich), a selective PPARA agonist and peroxisome proliferator, was tested for toxicity on zygotes $18-20 \mathrm{~h}$ post-hCG at concentrations of $0.1-10 \mu \mathrm{M}$ in KSOM. None of these concentrations affected the proportion of embryos developing to the blastocyst stage by $96 \mathrm{~h}$ post-hCG, so $10 \mu \mathrm{M}$ were selected for experiments. CHX (2 mg/l CHX, Sigma-Aldrich (Heo \& Han 2006)), and $\alpha$-amanitin (1 mg/l aAA, Fluka, 06422 from Sigma-Aldrich (Liu et al. 2004)), were used to inhibit translation and transcription respectively. DPI (Sigma-Aldrich), an irreversible inhibitor of flavoenzymes, particularly activated NADPH oxidase, with tenfold lower potency for NADH oxidase (Morre 2002), inhibits the production of peroxide by the blockade of several NADPdependent enzymes in the pentose phosphate pathway and tricarboxylic acid cycle. DPI was toxicity tested on zygotes $18-20 \mathrm{~h}$ post-hCG at concentrations of $0.01-10 \mu \mathrm{M}$ in KSOM, for 20 and $40 \mathrm{~min}$ exposure times and $20 \mathrm{~min}$ exposure to $0.1 \mu \mathrm{M}$. DPI was used in experiments because it did not affect blastocyst development and was the EC50 for HeLa cell NADPH oxidase (Morre 2002).

\section{Homogenization buffer}

Fifty millimoles Tris- $\mathrm{HCl} ; 150 \mathrm{mM} \mathrm{NaCl} ; 10 \mathrm{mM} \mathrm{NaF} ; 1 \mathrm{mM}$ $\mathrm{Na}_{3} \mathrm{VO}_{4} ; 1 \%$ Triton X-100; 1 complete protease inhibitor tablet per $50 \mathrm{ml}$ buffer (Roche Diagnostics Australia P/L).

\section{Laemmli sample buffer (Laemmli 1970)}

Ten percent SDS containing 1\% glycerol; $0.125 \mathrm{~g} / \mathrm{l}$ bromophenol blue; $0.125 \mathrm{~g} / \mathrm{l}$ xylene cyanol; $100 \mathrm{mM}$ dithiothreitol; $125 \mathrm{mM}$ Tris- $\mathrm{HCl}, \mathrm{pH}$ 6.8. Towbin transfer buffer (Towbin et al. 1979): 25 mM Tris; 192 mM glycine; 20\% methanol, pH 8.3. 


\section{Embryo collection and culture}

For some experiments (Figs 1-3), female 6-8-week-old Quackenbush mice from a high fecundity colony at the University of Queensland were injected with $10 \mathrm{IU}$ equine chorionic gonadotrophin (eCG, Folligon, Intervet $\mathrm{P} / \mathrm{L}$, East Bendigo, VIC, Australia) and $48 \mathrm{~h}$ later with $10 \mathrm{IU}$ hCG (Chorulon, Intervet). In experiments involving $\mathrm{H}_{2} \mathrm{O}_{2}$ (Figs 4-7), CBA/F1 hybrid mice from a colony at the University of Adelaide were injected with $5 \mathrm{IU}$ eCG (Sigma-Aldrich) and $48 \mathrm{~h}$ later with 5 IU hCG (Pregnyl; Organon Inc., Roseland, NJ, USA). Embryos were collected ex vivo at 24, 48, 72 and 96 h posthCG into M2 medium (Fulton \& Whittingham 1978), modified to contain $0.33 \mathrm{mM}$ sodium pyruvate and $4 \mathrm{~g} / \mathrm{l}$ of BSA and lacking glucose. Cumulus cells were removed where necessary using $0.5 \mathrm{~g} / \mathrm{l}$ hyaluronidase (Sigma-Aldrich) in glucose-free $M 2$, then washed thrice in fresh glucose-free $M 2$.

For experiments in vitro, zygotes ( $18 \mathrm{~h}$ post-hCG) were collected into glucose-free M2 and cultured in KSOM (Erbach et al. 1994) microdroplets under mineral oil at a density of 1 embryo/ $\mu \mathrm{l}$ in $4.7 \% \mathrm{O}_{2}, 4.7 \% \mathrm{CO}_{2}, 6.1 \% \mathrm{H}_{2} \mathrm{O}$ and $84.5 \% \mathrm{~N}_{2}$ at $37^{\circ} \mathrm{C}$ in a MINC incubator (Cook, Eight Mile Plains, QLD, Australia). KSOM contained $0 \mathrm{mM}$ (KSOM-G, glucose deprived) or $0.2 \mathrm{mM}$ glucose (KSOM, glucose supplied), and in some experiments variations of both KSOM and KSOM-G contained $10 \mu \mathrm{M}$ WY14643 or $0.1 \mu \mathrm{M}$ DPI or both. Cultured embryos were sampled at various stages for different experiments as described.

\section{mRNA analysis}

Total RNA was extracted from pools of 100 morphologically normal embryos collected after 30 or $54 \mathrm{~h}$ culture of zygotes collected at $18 \mathrm{~h}$ post-hCG, using phenol/chloroform and the RNeasy Mini Kit (Qiagen). For positive controls, RNA was extracted from mouse kidney or liver and $1 \mu \mathrm{g}$ used for RT. RNA was reverse transcribed and amplified by PCR (ArcellanaPanlilio \& Schultz 1993) using specific primers for Ppara: $5^{\prime}$ primer, 5'-tgatgagatgcgctctct-3'; $3^{\prime}$ primer, 5'-ggtagaagactgcagtag- $3^{\prime}$. Agarose gel ( $1 \%$ ) containing $0.5 \mathrm{mg} / \mathrm{l}$ ethidium bromide was used to resolve the 412-bp product. All cDNA samples were tested for genomic contamination using parallel PCR for mouse $\beta$-actin with primers: $5^{\prime}$ primer $5^{\prime}$-cgtgggccgcctaggcacca-3'; $3^{\prime}$ primer, 5'-ttggccttagggttcagggggg- $3^{\prime}$, which span the first intron of the mouse $\beta$-actin gene producing a 243-bp cDNA fragment and a 330-bp fragment from contaminating genomic DNA (Telford et al. 1990). Using Gel Extraction Kit (Qiagen), PCR products were extracted and ligated into a pGem-T Easy Vector (Promega), then amplified in transformed $\mathrm{DH} 5 \alpha$ Escherichia coli cells and purified using QIAprep Spin Miniprep Kit (Qiagen). EcoRI (Roche Diagnostics $\mathrm{GmbH}$ ) was used to digest purified plasmid clones, which were then sequenced by the Australian Genome Research Facility (Brisbane, QLD, Australia) to confirm sequence identity.

\section{Antisera \\ Affinity-purified anti-SLC16A7 IgG was raised in goats against a synthetic peptide mapping to the carboxy terminus of mouse}

SLC16A7 (14926, Santa Cruz Biotechnology, Santa Cruz, CA, USA). Anti-catalase antiserum was raised in rabbits against whole purified bovine liver catalase (200-4151, Rockland Immunochemicals Inc., Gilbertsville, PA, USA). Affinitypurified anti-PPARA IgG was raised in rabbits against a synthetic peptide corresponding to $\mathrm{N}$-terminal amino acids 1-18 of mouse PPARA (ab8934, Abcam, Cambridge, UK), amino acids 8-19 of serine-12-phosphorylated mouse PPARA (Abcam ab3484) and amino acids 14-25 of serine 21-phosphorylated mouse PPARA (Abcam ab3485). Secondary antibodies used for immunofluorescence or western immunoblotting included: FITC-conjugated rabbit anti-goat IgG (Calbiochem, EMD Chemicals Inc., SanDiego, CA, USA); FITC-conjugated goat anti-rabbit IgG (Calbiochem); Texas Red-conjugated goat anti-rabbit IgG (Calbiochem); HRP-labelled donkey anti-rabbit IgG (Amersham Biosciences); or rabbit anti-goat IgG (Progen Biosciences, Toowong, QLD Australia).

\section{Immunofluorescence}

Embryos fixed in 2\% paraformaldehyde in PBS ( $\mathrm{pH} 7.4$ ) underwent immunohistochemical processing (Pantaleon et al. 1997). Briefly, overnight incubation in primary antibody (2-10 mg/l) at $4{ }^{\circ} \mathrm{C}$ was followed by exposure to secondary antiserum for $1 \mathrm{~h}$ at room temperature. Samples were mounted in glycerol on concave glass slides and observed with a BioRad MRC-1024 confocal laser-scanning microscope mounted on a Zeiss (Oberkochen, Germany) Axioskop using a Zeiss Plan-APOCHROMAT $\times 60$ oil immersion objective. Where necessary for statistical analysis, after fixing, triplicate experimental sets were accumulated and held for $1-3$ days at $4{ }^{\circ} \mathrm{C}$ reducing variability.

\section{Western immunoblotting}

Mouse liver was homogenized in ice-cold homogenization buffer and centrifuged at $14000 \mathrm{~g}$ for $15 \mathrm{~min}$ at $4{ }^{\circ} \mathrm{C}$. Supernatant was removed and mixed with an equal volume of Laemmli sample buffer. Pools of 100 embryos in minimal medium were placed in $5 \mu$ l homogenization buffer with equal volume of Laemmli sample buffer. Liver and embryo samples were separated by PAGE and transferred via semi-dry electrotransfer to $0.45 \mu \mathrm{m}$ Immobilon-P PVDF membrane (Millipore P/L, North Ryde, NSW, Australia) using Towbin transfer buffer. Membranes were incubated at room temperature for $1 \mathrm{~h}$ in blocking solution of $7.5 \%$ BSA in PBS with $0.1 \%$ Tween-20, before incubation with primary antiserum $(0.1 \mathrm{mg} / \mathrm{l})$ overnight at $4{ }^{\circ} \mathrm{C}$. Finally, membranes were exposed for $1 \mathrm{~h}$ at room temperature to donkey anti-rabbit secondary antibody conjugated to HRP, and bands revealed with Supersignal West Femto Enhanced Chemiluminescence Detection Kit (Pierce Biotechnology Inc., Rockford, IL, USA) on X-ray film developed in a Kodak M35 X-Omat Processor (Kodak Australasia P/L).

\section{ROS assay}

Levels of ROS generation in embryos were assessed fluorometricly using $2^{\prime}, 7^{\prime}$-dichlorodihydrofluorescein diacetate (DCHFDA, Sigma-Aldrich) as previously described (Nasr-Esfahani et al. 1990). Esterases within the cells cleave 
the acetate groups trapping the reduced form of the probe (DCHF) intracellularly, which is readily oxidized to dichlorofluorescein (DCF) by $\mathrm{H}_{2} \mathrm{O}_{2}$ or $\mathrm{OH} \cdot$, but is relatively insensitive to (Vanden Hoek et al. 1997, Hempel et al. 1999). Zygotes (18-20 h post-hCG) from CBA/F1 hybrid mice collected into M2-lacking glucose were stripped of cumulus before random allocation into: KSOM; KSOM-G; KSOM-G+0.1 $\mu \mathrm{M} \mathrm{DPI}$ KSOM $+10 \mu \mathrm{M}$ WY14643 in DMSO (1:10 000); KSOM $+10 \mu \mathrm{M}$ WY14643 in DMSO+0.1 $\mu \mathrm{M}$ DPI; KSOM+DMSO (1:10 000). After $20 \mathrm{~min}$, embryos were washed free of DPI (flavoenzyme inhibitor) and returned to the same culture conditions without DPI. (At this time, embryos from each experimental group were randomly sampled and incubated for $30 \mathrm{~min}$ in $1 \mathrm{ml}$ media containing $10 \mu \mathrm{M}$ 6-carboxy-2 ${ }^{\prime}, 7^{\prime}$ dichlorodihydrofluorescein diacetate di-ester (CDCFDA) that fluoresces upon esterification to measure average total embryonic esterase activity.) After 1.5 or $3.5 \mathrm{~h}$, DCHFDA $(10 \mu \mathrm{M})$ was applied to each culture for $30 \mathrm{~min}$, and then embryos were washed free of BSA and placed on glass coverslips in $10 \mu \mathrm{l}$ BSA-free media. Green DCF or CDCF fluorescence from each embryo was quantified separately using a microfluorometer with filter excitation and emission wavelengths set at 460 and $510 \mathrm{~nm}$ respectively. Results were standardized by calculating the fluorescence ratio relative to the total average embryonic esterase activity.

\section{Statistical analysis}

Immunohistochemical expression levels were estimated from the pixel intensity of images using Image-J Software (National Institutes of Health, Bethesda, MD, USA). Embryos from three separate experiments underwent immunofluorescent staining at the same time, and all were analysed the next day using uniform confocal microscope settings to permit statistical analysis of staining intensity. Average grey level intensity from each embryo in each culture group was quantified with Image J, and mean grey levels per culture group per experiment were calculated. These data and those from measured ROS assays were compared by multi-variance ANOVA using Statgraphics Software. Values are presented are means \pm s.E.M. for triplicate experiments.

\section{Declaration of interest}

The authors declare that there is no conflict of interest that could be perceived as prejudicing the impartiality of the research reported.

\section{Funding}

This research was supported by grants to $P L$ Kaye and $M$ Pantaleon from the National Health and Medical Research Council of Australia (grant no. 210194) and to M Pantaleon, J G Thompson and P L Kaye from the NICHD (grant no. U01 HD 44664).

\section{Acknowledgements}

Sincere thanks to Michelle Lane for technical guidance with ROS experiments.

\section{References}

Arcellana-Panlilio MY \& Schultz GA 1993 Analysis of messenger RNA. Methods in Enzymology 225 303-328.

Bardot O, Clemencet MC, Passilly P \& Latruffe N 1995 The analysis of modified peroxisome proliferator responsive elements of the peroxisomal bifunctional enzyme in transfected HEPG2 cells reveals two regulatory motifs. FEBS Letters 360 183-186.

Berger PS \& Wood PA 2004 Disrupted blastocoele formation reveals a critical developmental role for long-chain acyl-CoA dehydrogenase. Molecular Genetics and Metabolism 82 266-272.

Biggers JD 1998 Reflections on the culture of the preimplantation embryo. International Journal of Developmental Biology 42 879-884.

Bispham J, Gardner DS, Gnanalingham MG, Stephenson T, Symonds ME \& Budge H 2005 Maternal nutritional programming of fetal adipose tissue development: differential effects on messenger ribonucleic acid abundance for uncoupling proteins and peroxisome proliferatoractivated and prolactin receptors. Endocrinology 146 3943-3949.

Bogdanova K, Uherkova L, Poczatkova H, Rypka M \& Vesely J 2007 mRNA levels of peroxisome proliferator-activated receptors and their coactivators are affected by glucose deprivation and oleate in human hepatoma hepG2 cells. Biomedical Papers of the Medical Faculty of the University Palacký, Olomouc, Czechoslovakia 151 237-245.

Boni R, Cuomo A \& Tosti E 2002 Developmental potential in bovine oocytes is related to cumulus-oocyte complex grade, calcium current activity, and calcium stores. Biology of Reproduction 66 836-842.

Braissant O, Foufelle F, Scotto C, Dauca M \& Wahli W 1996 Differential expression of peroxisome proliferator-activated receptors (ppars): tissue distribution of PPAR-alpha, -beta, and -gamma in the adult rat. Endocrinology 137 354-366.

Brinster RL 1965 Studies on the development of mouse embryos in vitro. IV. Interaction of energy sources. Journal of Reproduction and Fertility $\mathbf{1 0}$ 227-240.

Brown J \& Whittingham DG 1991 The roles of pyruvate, lactate and glucose during preimplantation development of embryos from F1 hybrid mice in vitro. Development 112 99-105.

Budge H, Gnanalingham MG, Gardner DS, Mostyn A, Stephenson T \& Symonds ME 2005 Maternal nutritional programming of fetal adipose tissue development: long-term consequences for later obesity. Birth Defects Research. Part C, Embryo Today: Reviews 75 193-199.

Cao C, Leng Y \& Kufe D 2003 Catalase activity is regulated by c-Abl and Arg in the oxidative stress response. Journal of Biological Chemistry 278 29667-29675.

Cebral E, Carrasco I, Vantman D \& Smith R 2007 Preimplantation embryotoxicity after mouse embryo exposition to reactive oxygen species. Biocell 31 51-59.

Chatot CL, Lewis-Williams J, Torres I \& Ziomek CA 1994 One-minute exposure of 4-cell mouse embryos to glucose overcomes morula block in CZB medium. Molecular Reproduction and Development 37 407-412.

Diradourian C, Girard J \& Pegorier JP 2005 Phosphorylation of PPARs: from molecular characterization to physiological relevance. Biochimie $\mathbf{8 7}$ 33-38.

Erbach GT, Lawitts JA, Papaioannou VE \& Biggers JD 1994 Differential growth of the mouse preimplantation embryo in chemically defined media. Biology of Reproduction 50 1027-1033.

Escher P, Braissant O, Basu-Modak S, Michalik L, Wahli W \& Desvergne B 2001 Rat PPARs: quantitative analysis in adult rat tissues and regulation in fasting and refeeding. Endocrinology 142 4195-4202.

Figueroa C, Kawada ME, Veliz LP, Hidalgo U, Barros C, Gonzalez S \& Santos MJ 2000 Peroxisomal proteins in rat gametes. Cell Biochemistry and Biophysics 32 259-268.

Fulton BP \& Whittingham DG 1978 Activation of mammalian oocytes by intracellular injection of calcium. Nature 273 149-151. 
Gardner DK, Lane M, Calderon I \& Leeton J 1996 Environment of the preimplantation human embryo in vivo: metabolite analysis of oviduct and uterine fluids and metabolism of cumulus cells. Fertility and Sterility 65 349-353.

Gelman L, Michalik L, Desvergne B \& Wahli W 2005 Kinase signaling cascades that modulate peroxisome proliferator-activated receptors. Current Opinion in Cell Biology 17 216-222.

Girnun GD, Domann FE, Moore SA \& Robbins ME 2002 Identification of a functional peroxisome proliferator-activated receptor response element in the rat catalase promoter. Molecular Endocrinology 16 2793-2801.

Gremlich S, Nolan C, Roduit R, Burcelin R, Peyot ML, DelghingaroAugusto V, Desvergne B, Michalik L, Prentki M \& Wahli W 2005 Pancreatic islet adaptation to fasting is dependent on peroxisome proliferator-activated receptor $\alpha$ transcriptional up-regulation of fatty acid oxidation. Endocrinology 146 375-382.

Haggarty P, Wood M, Ferguson E, Hoad G, Srikantharajah A, Milne E, Hamilton M \& Bhattacharya S 2006 Fatty acid metabolism in human preimplantation embryos. Human Reproduction 21 766-773.

Harris SE, Gopichandran N, Picton HM, Leese HJ \& Orsi NM 2005 Nutrient concentrations in murine follicular fluid and the female reproductive tract. Theriogenology 64 992-1006.

Hashimoto T, Cook WS, Qi C, Yeldandi AV, Reddy JK \& Rao MS 2000 Defect in peroxisome proliferator-activated receptor $\alpha$-inducible fatty acid oxidation determines the severity of hepatic steatosis in response to fasting. Journal of Biological Chemistry 275 28918-28928.

Hempel SL, Buettner GR, O'Malley YQ, Wessels DA \& Flaherty DM 1999 Dihydrofluorescein diacetate is superior for detecting intracellular oxidants: comparison with $2^{\prime}, 7^{\prime}$-dichlorodihydrofluorescein diacetate, 5(and 6)-carboxy-2', $7^{\prime}$-dichlorodihydrofluorescein diacetate, and dihydrorhodamine 123. Free Radical Biology \& Medicine 27 146-159.

Heo JS \& Han HJ 2006 PKC and MAPKs pathways mediate EGF-induced stimulation of 2-deoxyglucose uptake in mouse embryonic stem cells. Cellular Physiology and Biochemistry 17 145-158.

Hewitson LC \& Leese HJ 1993 Energy metabolism of the trophectoderm and inner cell mass of the mouse blastocyst. Journal of Experimental Zoology $267337-343$

Hillman N \& Flynn TJ 1980 The metabolism of exogenous fatty acids by preimplantation mouse embryos developing in vitro. Journal of Embryology and Experimental Morphology 56 157-168.

Hirotani M, Tsukamoto T, Bourdeaux J, Sadano H \& Osumi T 2001 Stabilization of peroxisome proliferator-activated receptor $\alpha$ by the ligand. Biochemical and Biophysical Research Communications 288 106-110.

Vanden Hoek TL, Shao Z, Li C, Schumacker PT \& Becker LB 1997 Mitochondrial electron transport can become a significant source of oxidative injury in cardiomyocytes. Journal of Molecular and Cellular Cardiology 29 2441-2450.

Issemann I \& Green S 1990 Activation of a member of the steroid hormone receptor superfamily by peroxisome proliferators. Nature 347 645-650.

Jansen S, Pantaleon M \& Kaye PL 2008 Characterization and regulation of monocarboxylate cotransporters Slc16a7 and Slc16a3 in preimplantation mouse embryos. Biology of Reproduction 79 84-92.

Kane MT 1979 Fatty acids as energy sources for culture of one-cell rabbit ova to viable morulae. Biology of Reproduction 20 323-332.

Krey G, Braissant O, L'Horset F, Kalkhoven E, Perroud M, Parker MG \& Wahli W 1997 Fatty acids, eicosanoids, and hypolipidemic agents identified as ligands of peroxisome proliferator-activated receptors by coactivator-dependent receptor ligand assay. Molecular Endocrinology 11 779-791.

Laemmli UK 1970 Cleavage of structural proteins during the assembly of the head of bacteriophage T4. Nature 227 680-685.

Lane M \& Gardner DK 2000 Lactate regulates pyruvate uptake and metabolism in the preimplantation mouse embryo. Biology of Reproduction 62 16-22.

Lane M \& Gardner DK 2007 Embryo culture medium: which is the best? Best Practice \& Research. Clinical Obstetrics \& Gynaecology 21 83-100.

Latruffe N, Cherkaoui Malki M, Nicolas-Frances V, Clemencet MC, Jannin B \& Berlot JP 2000 Regulation of the peroxisomal betaoxidation-dependent pathway by peroxisome proliferator-activated receptor $\alpha$ and kinases. Biochemical Pharmacology 60 1027-1032.
Lemberger T, Braissant O, Juge-Aubry C, Keller H, Saladin R, Staels B, Auwerx J, Burger AG, Meier CA \& Wahli W 1996a Ppar tissue distribution and interactions with other hormone-signaling pathways. Annals of the New York Academy of Sciences 804 231-251.

Lemberger T, Desvergne B \& Wahli W $1996 b$ Peroxisome proliferatoractivated receptors: a nuclear receptor signaling pathway in lipid physiology. Annual Review of Cell and Developmental Biology 12 335-363.

Liu H, Kim JM \& Aoki F 2004 Regulation of histone H3 lysine 9 methylation in oocytes and early pre-implantation embryos. Development 131 2269-2280.

Lonergan T, Bavister B \& Brenner C 2007 Mitochondria in stem cells. Mitochondrion 7 289-296.

Martin KL \& Leese HJ 1995 Role of glucose in mouse preimplantation embryo development. Molecular Reproduction and Development 40 436-443.

McClelland GB, Khanna S, Gonzalez GF, Butz CE \& Brooks GA 2003 Peroxisomal membrane monocarboxylate transporters: evidence for a redox shuttle system? Biochemical and Biophysical Research Communications 304 130-135.

Morre DJ 2002 Preferential inhibition of the plasma membrane NADH oxidase (NOX) activity by diphenyleneiodonium chloride with NADPH as donor. Antioxidants \& Redox Signaling 4 207-212.

Nagano M, Katagiri S \& Takahashi Y 2006 Relationship between bovine oocyte morphology and in vitro developmental potential. Zygote $\mathbf{1 4}$ 53-61.

Nasr-Esfahani MH, Aitken JR \& Johnson MH 1990 Hydrogen peroxide levels in mouse oocytes and early cleavage stage embryos developed in vitro or in vivo. Development 109 501-507.

Nemali MR, Reddy MK, Usuda N, Reddy PG, Comeau LD, Rao MS \& Reddy JK 1989 Differential induction and regulation of peroxisomal enzymes: predictive value of peroxisome proliferation in identifying certain nonmutagenic carcinogens. Toxicology and Applied Pharmacology 97 72-87.

Pantaleon M, Harvey MB, Pascoe WS, James DE \& Kaye PL 1997 Glucose transporter GLUT3: ontogeny, targeting, and role in the mouse blastocyst. PNAS 94 3795-3800.

Pantaleon M, Scott J \& Kaye PL 2008 Nutrient sensing by the early mouse embryo: hexosamine biosynthesis and glucose signaling during preimplantation development. Biology of Reproduction 78 595-600.

Piot C, Veerkamp JH, Bauchart D \& Hocquette JF 1998 Contribution of mitochondria and peroxisomes to palmitate oxidation in rat and bovine tissues. Comparative Biochemistry and Physiology. Part B, Biochemistry and Molecular Biology 121 185-194.

Poirier Y, Antonenkov VD, Glumoff T \& Hiltunen JK 2006 Peroxisomal beta-oxidation - a metabolic pathway with multiple functions. Biochimica et Biophysica Acta 1763 1413-1426.

Quinn P \& Whittingham DG 1982 Effect of fatty acids on fertilization and development of mouse embryos in vitro. Journal of Andrology 3 440-444.

Ralser M, Wamelink MM, Kowald A, Gerisch B, Heeren G, Struys EA, Klipp E, Jakobs C, Breitenbach M, Lehrach H et al. 2007 Dynamic rerouting of the carbohydrate flux is key to counteracting oxidative stress. Journal of Biology 6 1011-1018.

Ringseis R, Gutgesell A, Dathe C, Brandsch C \& Eder K 2007 Feeding oxidized fat during pregnancy up-regulates expression of PPAR $\alpha$ responsive genes in the liver of rat fetuses. Lipids in Health and Disease 6 6-18.

Sakkas D, Trounson AO \& Kola I 1989 In vivo cleavage rates and viability obtained for early cleavage mouse embryos in co-culture with oviduct cells. Reproduction Fertility and Development 1 127-136.

Schrader M \& Fahimi HD 2006 Peroxisomes and oxidative stress. Biochimica et Biophysica Acta 1763 1755-1766.

Sharifpanah F, Wartenberg M, Hannig M, Piper HM \& Sauer H 2008 Peroxisome proliferator-activated receptor $\alpha$ agonists enhance cardiomyogenesis of mouse ES cells by utilization of a reactive oxygen species-dependent mechanism. Stem Cells 26 64-71.

Shearer BG \& Hoekstra WJ 2003 Recent advances in peroxisome proliferator-activated receptor science. Current Medicinal Chemistry 10 267-280. 
Sterchele PF, Sun H, Peterson RE \& Vanden Heuvel JP 1996 Regulation of peroxisome proliferator-activated receptor- $\alpha$ mRNA in rat liver. Archives of Biochemistry and Biophysics 326 281-289.

Sugden MC, Bulmer K, Gibbons GF \& Holness MJ 2001 Role of peroxisome proliferator-activated receptor- $\alpha$ in the mechanism underlying changes in renal pyruvate dehydrogenase kinase isoform 4 protein expression in starvation and after refeeding. Archives of Biochemistry and Biophysics 395 246-252.

Teissier E, Nohara A, Chinetti G, Paumelle R, Cariou B, Fruchart JC, Brandes RP, Shah A \& Staels B 2004 Peroxisome proliferator-activated receptor $\alpha$ induces NADPH oxidase activity in macrophages, leading to the generation of LDL with PPAR- $\alpha$ activation properties. Circulation Research 95 1174-1182.

Telford NA, Hogan A, Franz CR \& Schultz GA 1990 Expression of genes for insulin and insulin-like growth factors and receptors in early postimplantation mouse embryos and embryonal carcinoma cells. Molecular Reproduction and Development 27 81-92.

Towbin H, Staehelin T \& Gordon J 1979 Electrophoretic transfer of proteins from polyacrylamide gels to nitrocellulose sheets: procedure and some applications. PNAS 76 4350-4354.

Vivancos AP, Castillo EA, Jones N, Ayte J \& Hidalgo E 2004 Activation of the redox sensor Pap1 by hydrogen peroxide requires modulation of the intracellular oxidant concentration. Molecular Microbiology $\mathbf{5 2}$ 1427-1435.

van der Vusse GJ, Glatz JF, Stam HC \& Reneman RS 1992 Fatty acid homeostasis in the normoxic and ischemic heart. Physiological Reviews 72 881-940.

Wilding M, Fiorentino A, De Simone ML, Infante V, De Matteo L, Marino M \& Dale B 2002 Energy substrates, mitochondrial membrane potential and human preimplantation embryo division. Reproductive Biomedicine Online 5 39-42.

Woods CG, Burns AM, Bradford BU, Ross PK, Kosyk O, Swenberg JA, Cunningham ML \& Rusyn I 2007 WY-14,643 induced cell proliferation and oxidative stress in mouse liver are independent of NADPH oxidase. Toxicological Sciences 98 366-374.

Yano S \& Yano N 2002 Regulation of catalase enzyme activity by cell signaling molecules. Molecular and Cellular Biochemistry 240 119-130.

Yano S, Yano N, Rodriguez N, Baek JH, Que X, Yamamura Y \& Kim SJ 1998 Suppression of intracellular hydrogen peroxide generation and catalase levels in CD8+T-lymphocytes from HIV+ individuals. Free Radical Biology \& Medicine 24 349-359.

Yano S, Arroyo N \& Yano N 2004 Catalase binds Grb2 in tumor cells when stimulated with serum or ligands for integrin receptors. Free Radical Biology \& Medicine 36 1542-1554.

Yeldandi AV, Rao MS \& Reddy JK 2000 Hydrogen peroxide generation in peroxisome proliferator-induced oncogenesis. Mutation Research $\mathbf{4 4 8}$ 159-177.

Zeron Y, Ocheretny A, Kedar O, Borochov A, Sklan D \& Arav A 2001 Seasonal changes in bovine fertility: relation to developmental competence of oocytes, membrane properties and fatty acid composition of follicles. Reproduction 121 447-454.

Received 6 February 2009

First decision 30 March 2009

Revised manuscript received 3 June 2009

Accepted 16 June 2009 